\title{
Hugh Huxley (1924-2013)
}

\section{Biophysicist who established the mechanism of muscle contraction.}

I $\mathrm{n}$ a career spanning more than 65 years, Hugh Huxley achieved his lifelong ambition of understanding how muscles contract.

Huxley, who died on 25 July after a heart attack, was born in 1924 in Cheshire, UK, and studied physics at Christ's College at the University of Cambridge, UK. His education was interrupted by service in the Royal Air Force from 1943 to 1947, testing height-tosurface (H2S) radar - a ground-scanning system used by bomber aircraft. There, he learned the importance of doing work himself, and experimenting with electrical and mechanical devices became a lifetime passion. Huxley was able to fix a wildly inaccurate version of $\mathrm{H} 2 \mathrm{~S}$ developed for east Asia by switching from a voltage-controlled display system, in which overheating was a problem, to a current-controlled system. He described the feat to me some 60 years later as his first 'eureka moment' - for which he was made a Member of the Order of the British Empire (MBE) in 1948.

With the confidence of youth, that same year, Huxley chose to study muscle structure using X-ray methods for his $\mathrm{PhD}$. He joined Max Perutz's group at the Medical Research Council (MRC) Unit for Research on the Molecular Structure of Biological Systems in Cambridge, with John Kendrew as his supervisor. As with radar, X-ray crystallography was in its infancy, and this project would test Huxley's talent for experimentation, attention to detail and determination to succeed.

Little was known then about the detailed structure of muscle. A pattern of dark and light bands had been identified with light microscopy, and the proteins actin and myosin were known to form filaments that interacted, although their exact location in muscle cells was unclear. From the analysis of X-ray patterns, Huxley identified big changes in the intensities of some reflections when muscles were contracted (when ATP, which provides cells with energy, is removed). He deduced the presence of a hexagonal array of two different types of filaments, and concluded that muscle contraction involved physical links between myosin and actin.

Needing visual evidence, he went to the Massachusetts Institute of Technology in Cambridge in late 1952. He was joined by the biophysicist Jean Hanson and, using both electron and light microscopy, they demonstrated the presence of two sets of overlapping filaments and found that the salt solutions that extract myosin removed only the optically dense A-bands (another eureka moment). Their 1953 Nature paper, together with earlier X-ray work, provided the key evidence for the 'sliding filament' model of muscle contraction.

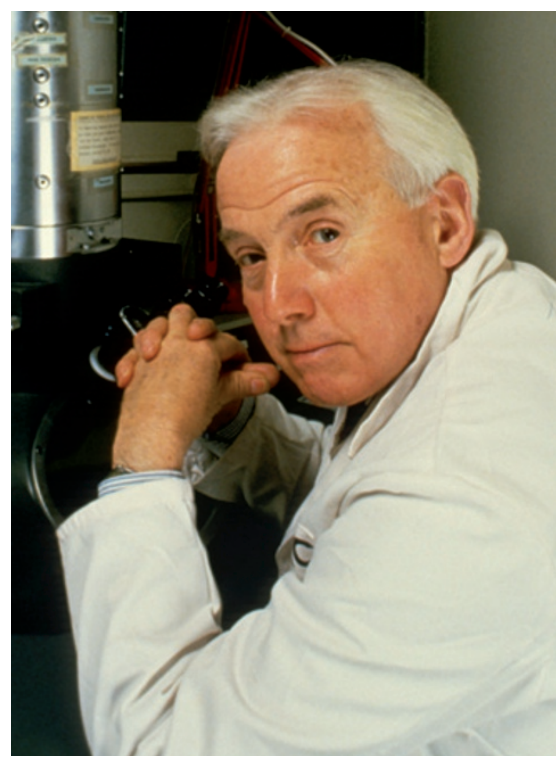

Muscle experts were sceptical, but a chance meeting with fellow Brit Andrew F. Huxley (no relation) at Woods Hole in Massachusetts lent Hugh's theory strong support. Andrew Huxley had come to similar conclusions using interference microscopy to analyse single muscle fibres, although without the fine detail revealed by electron microscopy. The two Huxleys agreed to publish simultaneously, and the papers appeared in Nature in May 1954, with Hugh Huxley's the more substantial, in my view. This was the defining moment in the study of muscle.

What made the filaments slide? In 1958, Huxley discovered myosin 'cross-bridges' These attach to actin in a herringbone fashion in the absence of ATP, and detach when ATP is present. They drive muscle motion like rowing oars.

In 1962, Huxley returned to Britain to join the newly opened MRC Laboratory of Molecular Biology in Cambridge (LMB), where he later became deputy director. Over the next 50 years he was relentless in his quest to understand cross-bridge movement. His seminal 1969 Science paper described the swinging cross-bridge model, and subsequent computer reconstructions showed how calcium ions regulated cross-bridge interaction. In 1970, using intense X-ray synchrotron radiation, Huxley began timeresolved studies of cross-bridge movement.

Huxley's move in 1988 to Brandeis University in Waltham, Massachusetts, as director of the Rosenstiel Basic Medical Sciences Research Center, gave him access to even more powerful X-ray sources, particularly at Argonne National Laboratory in Illinois. Improved detectors with high-sensitivity charge-coupled devices (used in digital cameras) enabled him to collect in milliseconds data that would have taken hours when he started out. With the atomic structures of actin and the myosin cross-bridge, along with other evidence, he wrote in the European Journal of Biochemistry in 2004 that he finally had direct evidence for the type of cross-bridge movement that he had postulated nearly 50 years earlier. It gave him great satisfaction that the mechanism by which myosin functions in muscle is replicated in almost all biological movement. His love for experimentation had delivered beyond his wildest dreams.

Hugh admired independence of spirit and enterprise, and he led by example. His personality reflected his strong humanist views. Outside science, he enjoyed travelling, sailing and skiing; he shared with his wife Frances a passion for theatre, relished a fine burgundy and loved the operas of Giacamo Puccini.

For the LMB's 50th anniversary in 2012, and with a new and greatly enlarged LMB opened in 2013, Hugh asked more than 40 academics who had visited the lab between 1957 and 1988 to write about how it had influenced their careers. These compiled writings, Memories and Consequences (MRC, 2013), provide fascinating reflections. The cell biologist Richard McIntosh described the atmosphere at the LMB as exuding "quality of thought, care in execution and energy in pursuit of excellence, reflecting the power of intelligent collaboration between labs with different kinds of expertise". There could be no more fitting epitaph for Hugh Huxley.

Alan Weeds was hired by Hugh Huxley in 1967 to establish a biochemistry group to study myosin, and worked on motile systems at the Laboratory of Molecular Biology in Cambridge, UK, for more than 40 years. He retired in 2005 and is a life fellow of Trinity College, University of Cambridge, UK. e-mail:agw22@cam.ac.uk 